\title{
ANNA-3 Associated Stiff-Person-Syndrome
}

\author{
Steven R. Zeiler ${ }^{1 *}$, Joseph Dedrick Jordan², Benjamin M. Greenberg ${ }^{3}$, Peter W. Kaplan ${ }^{4}$ \\ ${ }^{1}$ The Johns Hopkins Hospital, Department of Neurology, Pathology 627C 600 N. Wolfe Street, Baltimore, MD 21287 \\ 2University of North Carolina, 919.966.5547 \\ ${ }^{3}$ UT Southwestern Medical Center, 5323 Harry Hines Blvd., Dallas, TX 75390-9003 \\ ${ }^{4}$ The Johns Hopkins Bayview Medical Center, Department of Neurology, 4940 Eastern Avenue, Baltimore, MD 21224
}

\section{Introduction}

Paraneoplastic autoimmune syndromes include a heterogeneous group of neurological disorders caused by means other than metabolic and nutritional deficits, infections, coagulopathies, metastases, and side effects of cancer treatment. Antigenic proteins derived from the tumors are presumed to be the immunogens initiating the autoimmune responses.

The literature describes a group of paraneoplastic antibodies refered to as anti-neuronal nuclear antibodies (ANNA-1, -2, and -3 ), which are associated with a variety of syndromes, most notably localized to the cerebellum (Chan et al., 2001; Bataller and Dalmau, 2003; Toothaker and Rubin, 2009). The most recently described, ANNA-3, has been associated with sensory and sensorimotor neuropathies, cerebellar degeneration, as well as brain stem and limbic encephalopathies, often in the setting of lung malignancies (Chan et al., 2001). We describe here a novel presentation of a small cell lung cancer ANNA-3 positive paraneoplastic syndrome consisting of lower extremity dysfunction secondary to tonically active muscles. The clinical picture was most consistent with Stiff-Person-Syndrome (SPS).

\section{Report of a Patient}

A 68 year old Caucasian male with hypertension, COPD, and a 40 pack-year smoking history presented with progressive shortfunction for approximately one month. On admission, the patient noted 4 weeks of slowly progressive, severe lower extremity stiffness, an inability to stand secondary to his "feet and toes curling underneath" him, shooting pains distal to the knee brought on by movement, and very mild parasthesias distal to the ankle. Accompanying these complaints was an unintended 20 pound weight loss over a preceding 6 month period of time.

Physical examination revealed a thin, cognitively intact male with significantly increased muscle tone, especially in the lower extremities bilaterally, such that voluntary or passive dorsiflexion of the ankle was impossible. Persistence of tone was noted even while the patient was asleep. The patient also suffered from decreased muscle bulk of the arms and legs bilaterally. His muscle strength in the upper extremities was normal. In the lower extremities, his hip flexors were 4 out of 5 and knee flexors and extensors were normal power. Biceps, triceps, and brachioradialis stretch reflexes were 2 out of 4 ; patellar stretch reflexes were 3 out of 4 bilaterally. Plantar responses were extensor bilaterally. The patient's light touch, vibration, and pinprick sensation was mildly diminished distal to the ankles bilaterally. Peri-anal sensation was intact.

Laboratory analysis revealed normal Vitamin B12, homocysteine, ESR, HgA1C, TSH, and T4 values. CSF analysis revealed a normal protein, glucose, and cell count. Lyme serology was ness of breath, dyspnea on exertion, and lower extremity dys-

negative and RPR was nonreactive. MRI of the brain revealed evidence of previous ischemic strokes involving the anteromedial left frontal lobe and the posterolateral left frontal lobe as well as a pattern of white matter change consistent with microvascular ischemia. MRI of the cervical, thoracic, and lumbar spine revealed mild multilevel disc degeneration, but no gross evidence of cord inflammation, compression, or prominent disk protrusion. EMG revealed no radiculopathies and no abnormalities localized to the peripheral motor or sensory nerves; however, EMG did reveal continuous motor unit activity of both agonist and antagonist muscles.

A paraneoplastic panel of antibodies was obtained (Mayo clinic panel \#83380) which revealed a positive ANNA-3; however antiamphiphysin and anti-GAD65 antibodies were not detected. An extensive cancer work up revealed enlarged and metabolically active mediastinal lymph nodes. One of these lymph nodes was biopsied and was diagnostic for small cell lung cancer.

Over the ensuing months, the patient was treated with cisplatin and etoposide for his lung cancer; concomitantly, he was treated symptomatically with oral diazepam which ameliorated some of his increased tone. With this combined therapy, the patient experienced a progressive improvement in his neurological symptoms such that at one year follow-up, his neurological examination was unremarkable and he was able to ambulate normally. Repeat imaging found no evidence of malignancy. Benzodiazepines were slowly weaned off without ill effect and the patient has remained symptom free.

\section{Discussion}

The literature describes a group of paraneoplastic antibodies referred to as anti-neuronal nuclear antibodies (ANNA-1, -2, and -3), which are associated with a variety of symptoms, most notably localizing to the cerebellum (Chan et al., 2001; Bataller and Dalmau, 2003; Toothaker and Rubin, 2009). Chan et al. (2001) first described the ANNA-3 positive syndrome with a case series of 11 patients with the following findings: gait ataxia, numbness, and other uncommon abnormalities including slurred speech, blurred vision, dizziness, hyporeactive reflexes, head-

*Corresponding author: Steven R. Zeiler, The Johns Hopkins Hospital, Department of Neurology, Pathology 627C 600 N. Wolfe Street, Baltimore, MD 21287, Tel: 303-520-7404; E-mail: sz@jhmi.edu

Received December 02, 2009; Accepted December 24, 2009; Published December 24, 2009

Citation: Zeiler SR, Jordan JD, Greenberg BM, Kaplan PW (2010) ANNA3 Associated Stiff-Person-Syndrome. J Cancer Sci Ther 1: 001-002. doi:10.4172/1948-5956.1000014

Copyright: () 2010 Zeiler SR, et al. This is an open-access article distributed under the terms of the Creative Commons Attribution License, which permits unrestricted use, distribution, and reproduction in any medium, provided the original author and source are credited.

J Cancer Sci Ther
Volume 2(1) : 001-002 (2010) - 001 
Citation: Zeiler SR, Jordan JD, Greenberg BM, Kaplan PW (2010) ANNA-3 Associated Stiff-Person-Syndrome. J Cancer Sci Ther 1: 001-002. doi:10.4172/1948-5956.1000014

ache, and behavioral changes. Most of the 11 patients were found to have small cell cancer, usually originating from the lung. In contrast, we report a case of a small cell lung cancer ANNA-3 positive paraneoplastic syndrome consisting of lower extremity dysfunction secondary to tonically active agonist and antagonist muscles and no findings consistent with cerebellar pathology.

The clinical features of our patient resemble Stiff-Person-Syndrome (SPS; Murinson, 2004), another paraneoplastic mediated syndrome. Specifically, SPS patients often present with strong contractions of antagonistic muscle groups. Such contractions subsequently produce extraordinarily rigid postures seen to involve the legs and spine to a greater degree than rostral muscle groups. Patients often complain of pain in the involved muscles, especially with movement. SPS patients often possess hyperreflexia and extensor plantar responses. Unusual for SPS, our patient did not possess spinal involvement with an abnormal lumbar lordosis, hypertonic abdominal muscles, nor did he display clinical exacerbation to emotional triggers.

Associations between SPS and anti-GAD65 (Solimena et al., 1990; Bataller and Dalmau, 2003; Murinson, 2004) as well as anti-amphiphysin (De Camilli et al., 1993; Folli et al., 1993; Bataller and Dalmau, 2003; Murinson, 2004) have been described. However, to our knowledge, no association between SPS and any of the anti-neuronal nuclear antibodies (-1, -2, or 3 ) have been described. Thus, our patient provides a novel association between the clinical presentation of a stiff-person-likesyndrome and a rare antibody marker. This association underscores an emerging idea: paraneoplastic disorders do not represent individual syndromic disorders each associated with a specific autoantibody. Instead, paraneoplastic antibodies can be associated with overlapping clinical presentations and even coexist within a single patient (Bataller and Dalmau, 2003; Pittock et al., 2004).

Therefore, as the pantheon of paraneoplastic antibodies continues to increase, the prescence of a clinical paraneoplastic syndrome should prompt the search of a panel of paraneoplastic antibodies as well as any associated malignancy. As in the case discussed here, specific diagnostics and therapeutics can lead to dramatic clinical improvements.

\section{Disclosure}

The authors have reported no conflicts of interest. All authors have seen and approved this manuscript. Neither the submitted paper nor any similar paper, in whole or in part, other than an abstract or preliminary communication, has been or will be published in any other printed or digital publication.

\section{References}

1. Bataller L, Dalmau J (2003) Paraneoplastic neurologic syndromes: approaches to diagnosis and treatment. Semin Neurol 23: 215-24. »CrossRef » PubMed » Google Scholar

2. Chan KH, Vernino S, Lennon VA (2001) ANNA-3 anti-neuronal nuclear antibody: marker of lung cancer-related autoimmunity. Ann Neurol 50: 30111. »CrossRef » PubMed » Google Scholar

3. De Camilli P, Thomas A, Cofiell R, Folli F, Lichte B, et al. (1993) The synaptic vesicle-associated protein amphiphysin is the $128-\mathrm{kD}$ autoantigen of Stiff-Man syndrome with breast cancer. J Exp Med 178: 2219-23. »CrossRef » PubMed » Google Scholar

4. Folli F, Solimena M, Cofiell R, Austoni M, Tallini G, et al. (1993) Autoantibodies to a 128-kd synaptic protein in three women with the stiff-man syndrome and breast cancer. N Engl J Med 328: 546-51. »CrossRef » PubMed » Google Scholar

5. Murinson BB (2004) Stiff-person syndrome. Neurologist 10: 131-7. »CrossRef » PubMed » Google Scholar

6. Pittock SJ, Kryzer TJ, Lennon VA (2004) Paraneoplastic antibodies coexist and predict cancer, not neurological syndrome. Ann Neurol 56: 715-9. »CrossRef » PubMed » Google Scholar

7. Solimena M, Folli F, Aparisi R, Pozza G, De Camilli P (1990) Autoantibodies to GABA-ergic neurons and pancreatic beta cells in stiff-man syndrome. N Engl J Med 322: 1555-60. »CrossRef » PubMed » Google Scholar

8. Toothaker TB, Rubin M (2009) Paraneoplastic neurological syndromes: a review. Neurologist 15: 21-33. »CrossRef » PubMed » Google Scholar 